\title{
A Stochastic Model for Achieving Required Level of Availability Based on the Repair Rate Analysis
}

\author{
Nataša KONTREC, Milena PETROVIĆ, Stefan PANIĆ, Hranislav MILOŠEVIĆ
}

\begin{abstract}
The aim of this paper is to set framework for the repair rate in order to achieve required availability of a repairable system with alternating renewal process where the failure rate is Weibull distributed. In order to accomplish this goal, this paper proposes a novel model for a complete stochastic analysis of the repair rate. The resulting equation for probability density function of the repair rate enables precise modelling of the repair rate process for related values of availability and failure rate. The obtained results can be used for dynamic forecasting of system's characteristics, planning of maintenance activities, inventory and servicing capacities.
\end{abstract}

Keywords: alternating renewal process; availability; repair rate; stochastic analysis

\section{INTRODUCTION}

This paper considers a repairable system with failurerepair cycles modelled by renewal processes. Such system alternates from operational to failure state in a period of time [1]. In the moment of failure, the repairs or replacements of parts are conducted, after which this system returns to its operational state i.e. performs as brand new. If we denote the operational state as 1 , then we can present the time intervals where the system is in the aforesaid condition as $U=\left(U_{1}, U_{2}, U_{3}, \ldots\right)$. Similarly, if we denote the condition where the system is in the failure state with 0 then we can present the time intervals for system repairs with $D=\left(D_{1}, D_{2}, D_{3}, \ldots\right)$. Moreover, let us assume that $T=\left(\left(U_{1}, D_{1}\right),\left(U_{2}, D_{2}\right), \ldots\right)$ is a sequence of interdependent identically distributed intervals. Although these intervals are independent, $D_{n}$ can be expressed with the use of $U_{n}$ (i.e. for $n \in N+$. $D_{n}$ can be presented in function of $\left.U_{n}\right)$, and vice versa. Therein $E(U)$ represents the mean time to failure $(M T T F)$ while $E(D)$ represents the mean time required for the system to return to the operational state i.e. the mean time to repair (MTTR). Several important applications of the alternating renewal process are provided in papers [2] and [3].

The alternating renewal process is often used in order to determine the availability of a particular system, as the most common measure of efficiency of repairable systems $[4,5]$. Numerous factors affect the availability, such as system's reliability, spare parts' availability, system's maintenance etc. The availability is defined as a probability that the system will perform its function in a period of time [6]. The limiting availability or steady state availability is most commonly used to determine the long-run performance of a system [7].

$$
A=\lim _{t \rightarrow \infty} A(t)
$$

If the key renewal theorem is applied, as presented in paper [8], the previous formula can be reduced as follows:

$$
A=\frac{E(U)}{E(U)+E(D)} .
$$

As stated previously $E(U)$ is $M T T F$, while $E(D)$ is $M T T R$, so the expression for availability can be reduced to the well known equation:

$$
A=\frac{M T T F}{M T T F+M T T R}
$$

Many papers dealing with the system's availability assessments exist at present time. In papers [9, 10], the author determines the steady state availability and trust intervals in the case where repair time has a lognormal distribution. The steady state availability and methods to determine this parameter for repairable systems have been examined in papers [11-13]. Significant contributions concerning determining the availability in repairable systems which function under maintenance contracts were given in papers [14-18]. They acknowledged that the system's availability primarily depends on the system's reliability, MTTF, number of spare parts in inventory and mean time required to return the system to operational state. A similar problem was further examined in paper [19] concluding that the system's repair time has the highest effect on system's availability. Due to that reason, we have decided to examine the system's repair time as a stochastic process, with the aim to determine the repair rate without having the system's availability level falling below the set limits.

\section{MATHEMATICAL MODEL FOR REPAIR RATE ANALYSIS}

The model presented in this paper is based on several assumptions. Firstly, the observed repairable system can be modelled with the alternating renewal process. Then, we are assuming that the system behaves like brand new, after the repairs had been made. Moreover, the failure rate has the Weibull distribution. In papers $[20,21]$ the failure rate was modelled by the Rayleigh distribution but according to [22-25] this parameter can also be modelled by using the Weibull distribution. Actually, according to [26], the failure rate of mechanical and electrical components has a bath-tub shape. It was shown that the Weibull distribution is very flexible in modelling various types of lifetime distributions so it can be used to model any of the three parts in a bath-tub curve (early "infant mortality" failure, 
constant (random) failure and increasing ("wear out") failure.

According to the aforementioned, if the system's failure time is Weibull distributed, the MTTF can be determined with the following Eq. (4):

$$
\begin{aligned}
& \text { MTTF }=\int_{0}^{\infty} t p_{\text {Weibul } l}(t) \mathrm{d} t= \\
& =\int_{0}^{\infty} t \frac{\beta t^{\beta-1}}{\omega^{\beta}} \exp \left(-\frac{t}{\omega}\right)^{\beta} \mathrm{d} t=\Gamma\left(1+\frac{1}{\beta}\right) \omega .
\end{aligned}
$$
in [27]:

Let denote $\lambda$ as a measure of failure rate as presented

$$
\begin{aligned}
& \lambda=\frac{1}{M T T F}=\frac{1}{\int_{0}^{\infty} t \frac{\beta t^{\beta-1}}{\omega^{\beta}} \exp \left(-\frac{t}{\omega}\right)^{\beta} \mathrm{d} t}= \\
& =\frac{1}{\Gamma\left(1+\frac{1}{\beta}\right) \omega} .
\end{aligned}
$$

In the Eqs. (4) and (5), $\omega$ and $\beta$ are parameters of the Weibull distribution $-\beta$ denotes shape parameter while $\omega$ denotes characteristic life parameter. Since the system repair rate, denoted as $\mu$, is equal to the reciprocal value of the mean time to repair (MTTR), the Eq. (3) can be presented as:

$$
A=\frac{\mu}{\mu+\lambda}
$$

Now, knowing that the second moment of Weibull distribution is:

$$
E\left(t^{2}\right)=\Gamma\left(1+\frac{2}{\beta}\right) \omega=x
$$

we can determine the distribution parameteras:

$$
\omega=\frac{x}{\Gamma\left(1+\frac{2}{\beta}\right)}
$$

By replacing $\omega$ in the Eq. (5) the failure rate transforms into:

$$
\lambda=\frac{\Gamma\left(1+\frac{2}{\beta}\right)}{\Gamma\left(1+\frac{1}{\beta}\right) x} .
$$

Using the Eq. (9) we can calculate the value of $x$ as in the Eq. (10)

$$
x=\frac{\Gamma\left(1+\frac{2}{\beta}\right)}{\Gamma\left(1+\frac{1}{\beta}\right) \lambda} .
$$

Determining the system's failure rate is a complex process and due to its stochastic nature the random variable $x$ can be considered as random variable that changes at significantly slower rate than random variable $t$ described with the Weibull model. As is known from the theory of stochastic processes [28] in the case where $x \approx t^{2}$ and random variable $t$ is described with the Weibull model, then the slow changes of the random variable $x$ can be presented as a stochastic process with exponential distribution as in the Eq. (11)

$p_{x}(x)=\frac{\exp \left(-\frac{x}{x_{0}}\right)}{x_{0}}, x>0, x_{0}=E(x)$.

The probability density function (PDF) of failure rate can now be presented with the following transformation:

$p(\lambda)=p_{x}\left(\frac{\Gamma\left(1+\frac{2}{\beta}\right)}{\Gamma\left(1+\frac{1}{\beta}\right)}\right)\left|\frac{d_{x}}{d_{\lambda}}\right|$,

where $\left|\frac{d_{x}}{d_{\lambda}}\right|$ can be determined as in (13)

$\left|\frac{d_{x}}{d_{\lambda}}\right|=\frac{\Gamma\left(1+\frac{2}{\beta}\right)}{\Gamma\left(1+\frac{1}{\beta}\right) \lambda^{2}}$

Now, by replacing the Eq. (12) and (13) into (11), we get the following equation failure rate PDF:

$p(\lambda)=\frac{\Gamma\left(1+\frac{2}{\beta}\right) \exp \left(-\frac{\Gamma\left(1+\frac{2}{\beta}\right)}{\Gamma\left(1+\frac{1}{\beta}\right) \lambda x_{0}}\right)}{\Gamma\left(1+\frac{1}{\beta}\right) \lambda^{2} x_{0}}$

Based on the Eq. (6), the failure rate is $\lambda=\frac{1-A}{A} \mu$ with the Jacobian transformation $\left|\frac{d_{\lambda}}{d_{\mu}}\right|=\frac{1-A}{A}$ while the repair rate can be expressed as $\mu=\frac{A \lambda}{1-A}$ with PDF: 
$p(\mu)=p_{\lambda}\left(\frac{A}{1-A}\right)\left|\frac{d_{\lambda}}{d_{\mu}}\right|$.

According to the previous equations we can now determine the PDF repair rate as in (16)

$$
\begin{aligned}
& p(\mu)= \\
& =\frac{\Gamma\left(1+\frac{2}{\beta}\right) A}{\Gamma\left(1+\frac{1}{\beta}\right)(1-A) \mu^{2} x_{0}} \exp \left(-\frac{\Gamma\left(1+\frac{2}{\beta}\right) A}{\Gamma\left(1+\frac{1}{\beta}\right)(1-A) \mu x_{0}}\right) .
\end{aligned}
$$

At the same time, the Eq. (16) presents one of the major contributions stated in this paper. It provides a precise mathematical characterization of a stochastic process that describes the repair time. The PDF expression for the repair rate enables precise modelling of the repair rate process for related values of availability. This can be used for dynamic forecasting of system's characteristics through simulation of the repair rate process by generating samples.

In order to further analyze the repair rate, the cumulative distribution function $(\mathrm{CDF})$ is provided:

$$
\begin{aligned}
& F(\mu)= \\
& =\frac{\Gamma\left(1+\frac{2}{\beta}\right) A}{\Gamma\left(1+\frac{1}{\beta}\right)(1-A) x_{0}} \int_{0}^{\mu} \frac{1}{\mu^{2}} \exp \left(-\frac{\Gamma\left(1+\frac{2}{\beta}\right) A}{\Gamma\left(1+\frac{1}{\beta}\right)(1-A) \mu x_{0}}\right) \mathrm{d} \mu .
\end{aligned}
$$

By solving the integral in the previous equation, the expression for the CDF function can be presented as:

$$
F(\mu)=\frac{A^{2}}{(1-A)^{2}}\left(1-\exp \left(-\frac{\Gamma\left(1+\frac{2}{\beta}\right) A}{\left.\Gamma\left(1+\frac{1}{\beta}\right)(1-A) \mu x_{0}\right)}\right) .\right.
$$

In order to obtain more precise data on the repair rate we can now apply the inverse sampling method. If we state that $y=F(\mu)$ where $y$ is uniformly distributed in interval $[0,1]$ then the inverse CDF is $F^{-1}(\mu)=y^{-1}$. Having this in mind, we can transform the previous equation into:

$$
\ln \left(\frac{(1-A)^{2}}{A^{2}}(1-y)\right)=\frac{\Gamma\left(1+\frac{2}{\beta}\right) A}{\Gamma\left(1+\frac{1}{\beta}\right)(A-1) \mu x_{0}},
$$

and determine the repair rate samples as in (20)

$$
\mu=\frac{\Gamma\left(1+\frac{2}{\beta}\right) A}{\Gamma\left(1+\frac{1}{\beta}\right)(A-1) x_{0} \ln \left(\frac{(1-A)^{2}}{A^{2}} y\right)}
$$

\section{NUMERICAL RESULTS}

In order to verify the mathematical model from the previous section we have used data from the case study presented in paper [29]. The MTTF data for the following subsystems for railway signalling are provided in this study:

- Interlocking: As input, receives data from different systems and calculates output which is then used to improve traffic safety

- Track circuit: Used to locate trains

- Balise group: Sends data on speed limits, driving limitations etc. from tracks to signalization system

- Level crossing: Coordinates railway traffic

- Signalling board: Provides timely information regarding tunnels, bridges, speed limits etc.

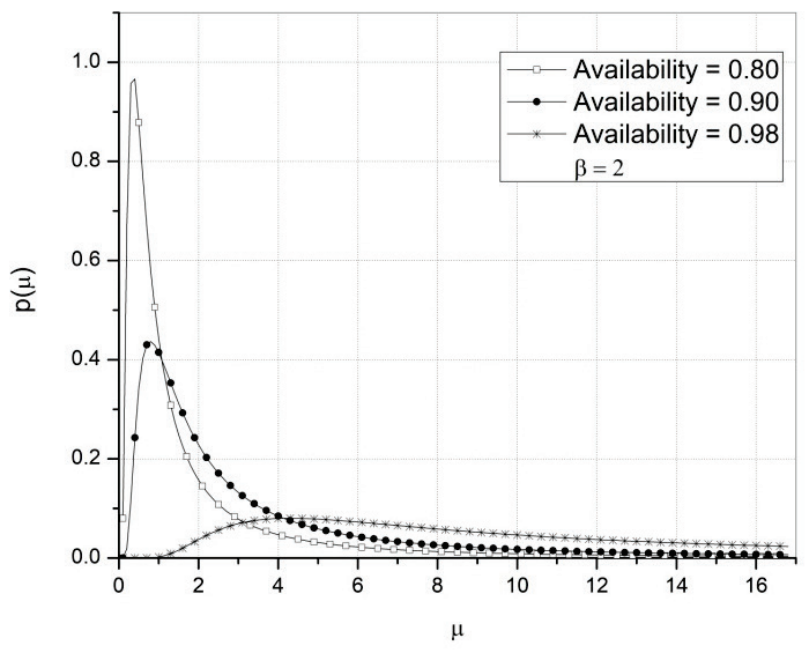

Figure 1 PDF of failure rate for Balise group

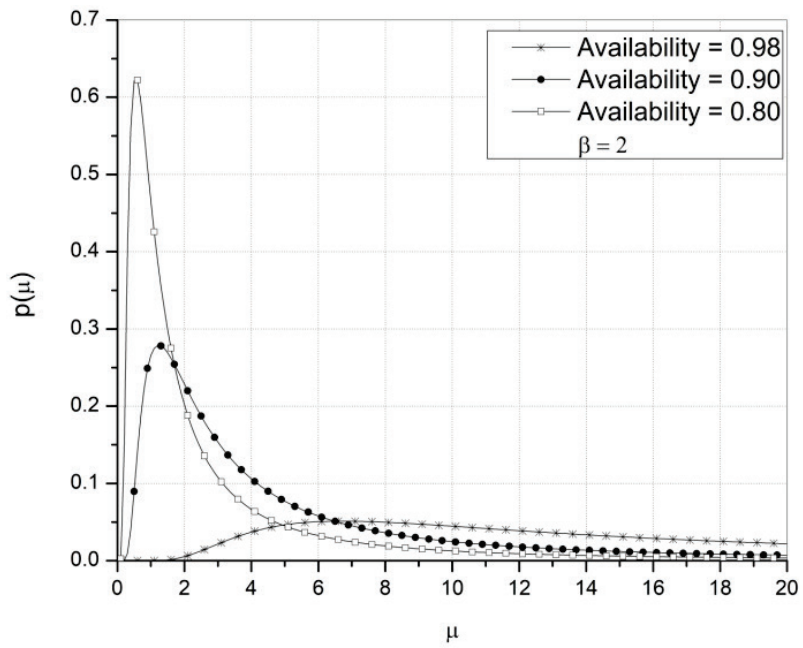

Figure 2 PDF of failure rate for Interlocking

It was determined that the MTTF for subsystem Interlocking is 2.8581 years, for Balise group 4.767, for 
Level crossing 2.286, for Signal 2,4663 and for Track circuit 2.004 .
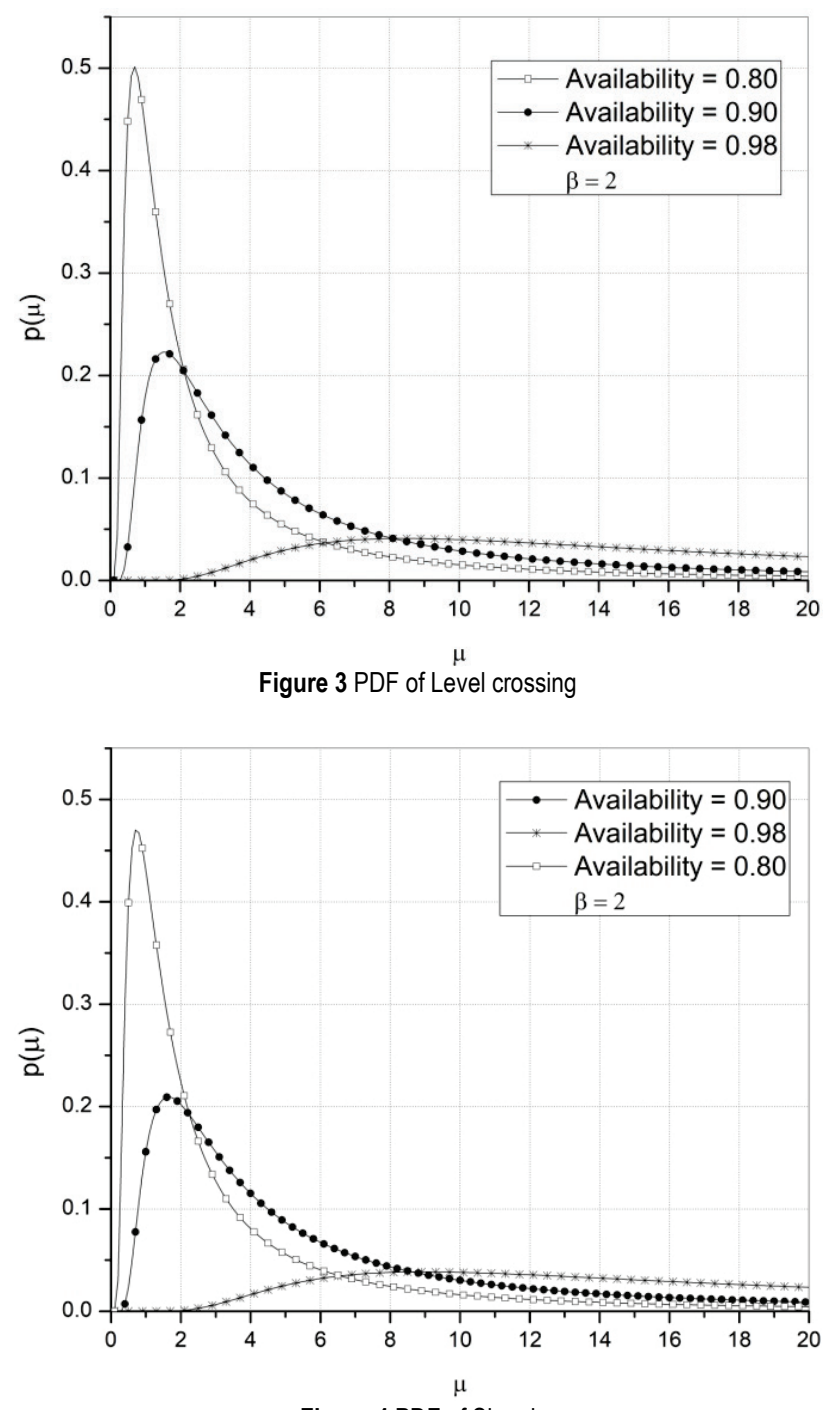

Figure 4 PDF of Signal

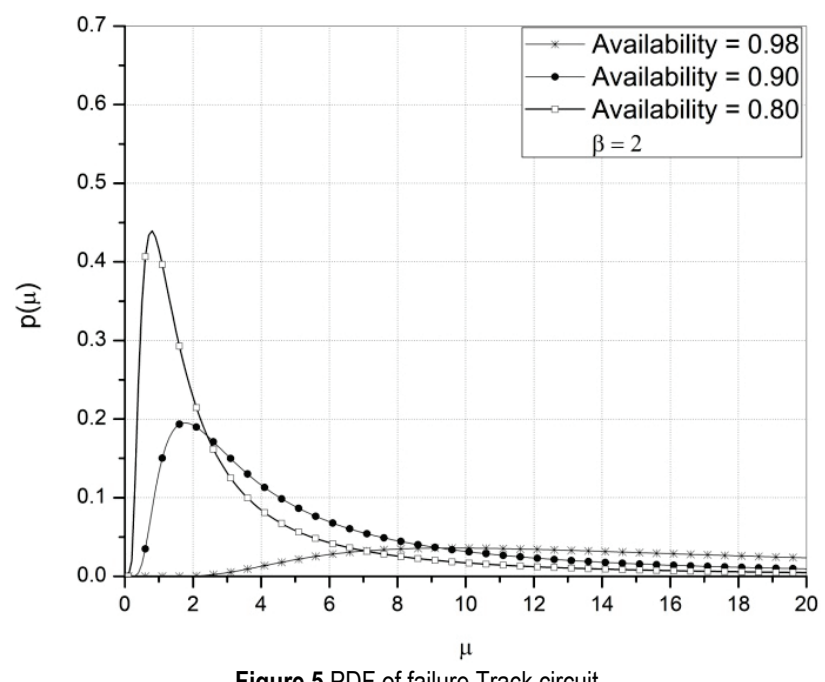

Figure 5 PDF of failure Track circuit

Based on the previous model, the PDF function depending on the required availability was presented for each sub-system.

Fig. 1 represents the PDF for the sub-system of Balise group for randomly selected values of sub-system availability. The system's availability in this specific example is $80 \%, 90 \%$ and $98 \%$ in proportion to time the system is in operational condition. It is possible to take into consideration other values of availability depending on the observed system and previously set demands. Likewise, Figs. 2, 3, 4 and 5 represent the PDF of failure rates for other sub-systems: Interlocking, Level crossing, Signal and Track circuit.

Based on the previously presented figures we can determine the probability that the repair rate will take one of the offered values. That information, together with the CDF inverse sampling, can be useful for planning the system's maintenance activities, number of service stations, spare parts and manpower required for maintenance.

\section{CONCLUSION}

Related researches of repairable systems' maintenance processes showed that both reliability and repair rate have significant impact on availability of such systems. In this paper we studied a system which can be modelled with the alternating renewal process. We assumed that the failure rate is Weibull distributed and that the MTTF is a predetermined value. Also, after repairs, the system returned to its original state and performed as new. In accordance with these assumptions, a novel model for determining the characteristics of the repair rate was formulated. We determined the expression for the repair rate's $\mathrm{PDF}$ and $\mathrm{CDF}$ which represents a precise mathematical characterization of the repair rate as a stochastic process. Using this expression can result in exact repair rate sample values for corresponding values of availability. In this way, by simulating the repair rate process through generating its samples, we can predict the system's dynamic characteristics. In Numerical result section, the previously described model was applied to a specific example i.e. five sub-systems of Railway Signalling System and graphical presentation of the PDF for each sub-system was provided. This model can be applied in the same manner to other repairable systems which can be modelled with the alternating renewal process. In addition, other values can be selected for availability. The obtained results can be further utilized in planning the maintenance activities, inventory, service systems and number of required employees, in the process of system maintenance.

\section{Acknowledgments}

This work was funded by the framework of Competitiveness Enhancement Program of the National Research Tomsk Polytechnic University, Russia and supported in part by the Serbian Ministry of Education, Science and Technological Development, Projects \#TR 35030 .

\section{REFERENCES}

[1] Wolstenholme L. C. (1999). Reliability Modeling. A Stochastic Approach, CRC Press, USA.

[2] Barlow, R. E. \& Proschan, F. (1965). Mathematical Theory of Reliability. New York, NY, USA: Wiley 
[3] Nakagawa, T. (2005) Maintenance Theory of Reliability. London, U. K.: Springer-Verlag

[4] Pham-Gia, T. \& Trukkan, N. (1999), System availability in a gamma alternating renewal process. Naval Research Logistics, 46, 822-844. https://doi.org/10.1002/(SICl)15206750(199910)46:7<822::AID-NAV5>3.0.CO;2-D

[5] Yao, K. \& Gao, J. (2015). Uncertain random alternating renewal process with application to interval availability. IEEE Trans. Fuzzy Syst., 23(5), 1333-1342. https://doi.org/10.1109/TFUZZ.2014.2360551

[6] Barlow, R. E. \& Proschan, F. (1975). Statistical theory of reliability and life testing. Probability Models. New York: Holt, Rinehart and Winston.

[7] Gamiz, M. L., Kulasekera, K. B., Limnios, N. \& Lindqvist B.H. (2011). Applied Nonparametric Statistics in Reliability. Springer-Verlag London. https://doi.org/10.1007/978-0-85729-118-9

[8] Ross, S. M. (1992). Applied probability models with optimization applications. New York: Courier Dover Publications

[9] Ananda, M. M. A. (2003). Confidence intervals for steady state availability of a system with exponential operating time and lognormal repair time. Applied Mathematics and Computation, 137(2-3), 499-509. https://doi.org/10.1016/S0096-3003(02)00155-8

[10] Ananda, M. M. A. \& Gamage, J. (2004). On steady state availability of a system with lognormal repair time. Applied Mathematics and Computation, 150(2), 409-416. https://doi.org/10.1016/S0096-3003(03)00281-9.

[11] Claasen, S. J., Joubert, J. W., \& Yadavalli, V. S. S. (2004). Interval estimation of the availability of a two unit standby system with non instantaneous switch over and "dead time". Pakistan Journal of Statistics, 20(1), 115-122.

[12] Hwan Cha, J., Sangyeol, L., \& Jongwoo, J. (2006) Sequential confidence interval estimation for system availability. Quality and Reliability Engineering International, 22, 165-176. https://doi.org/10.1002/qre.693

[13] Ke, J. C. \& Chu, Y. K. (2007). Nonparametric analysis on system availability: confidence bound and power function. Journal of Mathematics and Statistics, 3(4), 181-187.

[14] Kang, K., Doerr, K. H., \& Sanchez, S. M. (2006). A Design of Experiments Approach to Readiness Risk Analysis. Proceedings of the $38^{\text {th }}$ conference on Winter simulation (WSC '06), L. Felipe Perrone, Barry G. Lawson, Jason Liu, and Frederick P. Wieland (Eds.). Winter Simulation Conference, 1332-1339. https://doi.org/10.1109/WSC.2006.323232

[15] Kim, S. H., Cohen, M. A., \& Netessine, S. (2007) Performance contracting in after-sales service supply chains. Management Science, 53(12), 1843-58. https://doi.org/10.1287/mnsc.1070.0741

[16] Kim, S. H., Cohen, M. A., \& Netessine, S. (2007). Reliability or inventory? Contracting strategies for aftersales product support. Working Paper. OPIM Department, The Wharton School.

[17] Nowicki, D., Kumar, U. D., Steudel, H. J., \& Verma, D. (2008). Spares provisioning under performance-based logistics contract: profit-centric approach. Journal of the Operational Research Society, 59(3), 342-52. https://doi.org/10.1057/palgrave.jors.2602327

[18] Öner, K. B., Kiesmüller, G. P. \& van Houtum, G. J. (2010). Optimization of component reliability in the design phase of capital goods. European Journal of Operational Research, 205(3), 615-24. https://doi.org/10.1016/j.ejor.2010.01.030

[19] Mirzahosseinian, H. \& Piplani, R. (2011). A study of repairable parts inventory system operating under performance-based contract. European Journal of Operational Research. 214(2), 256-61. https://doi.org/10.1016/j.ejor.2011.04.035
[20] Kontrec, N., Milovanović, G., Panić, S., \& Milošević, H. (2015). A Reliability-Based Approach to Nonrepairable Spare Part Forecasting in Aircraft Maintenance System, Mathematical Problems in Engineering, 2015, 1-7. https://doi.org/10.1155/2015/731437

[21] Kontrec, N., Panić S., Petrović, M., \& Milošević, H. (2018). A stochastic model for estimation of repair rate for system operating under performance based logistics. Eksploatacja I Niezawodnosc - Maintenance and Reliability, 20(1), 68-72. https://doi.org/10.17531/ein.2018.1.9

[22] Kontrec, N. \& Panić, S. (2017). Spare Parts Forecasting Based on Reliability, System Reliability, Constantin Volosencu, IntechOpen. https://doi.org/10.5772/intechopen.69608

[23] Mudholkar, G. S. \& Srivastava, D. K. (1993). Exponentiated Weibull family for analyzing bathtub failure rate data. IEEE Transactions on Reliability, 42, 299-302. https://doi.org/10.1109/24.229504

[24] Xie, M., Tang, Y., \& Goh, T. N. (2002). A modified Weibull extension with bathtub-shaped failure rate function. Reliability Engineering \& System Safety, 76(3), 279-285. https://doi.org/10.1016/S0951-8320(02)00022-4

[25] Carrasco, J. M. F., Ortega, E. M. M., \& Cordeiro, G. M. (2008). A generalized modified Weibull distribution for lifetime modeling. Computational Statistics \& Data Analysis, 53(2), 450-462. https://doi.org/10.1016/j.csda.2008.08.023

[26] Xie, M. \& Lai, C. D. (1996). Reliability analysis using an additive Weibull model with bathtub-shaped failure rate function. Reliability Engineering and System Safety 52, 8793. https://doi.org/10.1016/0951-8320(95)00149-2

[27] Pham, H. (2006). System Reliability Concepts. In: System Software Reliability. Springer Series in Reliability Engineering. Springer, London. https://doi.org/10.1007/1-84628-295-0_2

[28] Leemis, L. \& McQueston, J. (2008) Univariate distribution relationships. The American Statistician, 62, 45-53. https://doi.org/10.1198/000313008X270448

[29] Morant, A., Gustafson, A., Söderholm, P., Larsson-Kråik, P., \& Kumar, U. (2016). Safety and availability evaluation of railway operation based on the state of signalling systems. Proceedings of the Institution of Mechanical Engineers, Part F: Journal of Rail and Rapid Transit, 231(2), 226-238. https://doi.org/10.1177/0954409715624466

\section{Contact information:}

\section{Nataša KONTREC, Assistant Professor}

(Corresponding author)

Faculty of Sciences and Mathematics, University of Priština,

Lole Ribara 29, 38220, Kosovska Mitrovica, Serbia

natasa.kontrec@pr.ac.rs

\section{Milena PETROVIĆ, Assistant Professo}

Faculty of Sciences and Mathematics, University of Priština

Lole Ribara 29, 38220, Kosovska Mitrovica, Serbia

milena.petrovic@pr.ac.rs

Stefan PANIĆ, Associate Professor

(1) National Research Tomsk Polytechnic University, Sovetskaya 84/3, 634050 Tomsk, Russian Federation

(2) Faculty of Sciences and Mathematics, University of Priština,

Lole Ribara 29, 38220, Kosovska Mitrovica, Serbia

stefanpnc@tpu.ru

Hranislav MILOŠEVIĆ, Professor

Faculty of Sciences and Mathematics, University of Priština,

Lole Ribara 29, 38220, Kosovska Mitrovica, Serbia

hranislav.milosevic@pr.ac.rs 